\title{
Prognosis after Early Discharge from Hospital of Patients with Acute Myocardial Infarction
}

\author{
A. A. JENNIFER ADGEY \\ From Royal Victoria Hospital, Belfast 12, Northern Ireland
}

It has been established that 60 to 80 per cent of deaths from acute myocardial infarction occur within 12 hours of the onset of symptoms (Yater et al., 1948; Bainton and Peterson, 1963). The majority of these deaths occur before the patients reach hospital (McNeilly and Pemberton, 1968). The efforts directed towards lowering the mortality from acute myocardial infarction which are most likely to succeed are those that aim at getting intensive care conditions to the patient as soon as possible after the onset of symptoms. To achieve the rapid institution of intensive care, a mobile intensive care unit has been described (Pantridge and Geddes, 1966, 1967). The general adoption of the mobile intensive care unit will mean that a greater number of patients will survive to reach hospital. This may result in problems connected with the availability of hospital beds. These problems might be solved in part if a significant number of patients with acute myocardial infarction were discharged after a shorter period in hospital than is usually advocated (Brit. med.F., 1968).

A unique opportunity of assessing the effects of early discharge presented itself, since it had been the practice of one general medical unit in this hospital to discharge patients much earlier than is usually considered advisable.

\section{Patients and Methods}

With the exception of one patient whose record could not be traced all records were examined of those patients aged 70 years or less who were admitted to this unit with an acute myocardial infarction during the period June 1962 to December 1964. In all, 185 patients survived their period in hospital. The diagnosis of myocardial infarction was established by the following criteria: (a) pathological $Q$ waves on the electrocardiogram accompanied by a rise of the ST segment and subsequent $T$ wave inversion, or (b) changes in the $S T$

Received April 10, 1969. segment and $T$ wave suggestive of infarction accompanied by a significant and transient rise in serum aspartate aminotransferase.

Because of complications, in particular serious cardiac arrhythmias, cardiac failure, AV block, or coincidental medical conditions, 82 patients were in hospital for more than 18 days. The remaining 102 patients were discharged 18 days or less after admission. This communication records the data of these 102 patients. Particular attention was directed to the complications in the 14 days after discharge, complications that might possibly have been prevented by a more prolonged period in hospital.

Age and sex of the 102 patients are shown in Table I and details of the site of infarction in Table II. Eighty-

TABLE I

AGE AND SEX OF PATIENTS

\begin{tabular}{c|c|c}
\hline Age (yr.) & Men & Women \\
\hline $30-40$ & 3 & 0 \\
$41-50$ & 22 & 2 \\
$51-60$ & 37 & 6 \\
$61-70$ & 20 & 12 \\
\hline Total & 82 & 20 \\
Average age & 54 yr. & 60 yr. \\
\hline
\end{tabular}

TABLE II

DETAILS OF INFARCTION

\begin{tabular}{l|c}
\hline \multicolumn{1}{c|}{ Site of infarct } & No. \\
\hline Diaphragmatic & 46 \\
Antero-lateral & 42 \\
Antero-septal & 8 \\
Diaphragmatic and antero-septal & 6 \\
\hline
\end{tabular}

two of the patients were men (average age 54 years) and 20 were women (average age 60 years). Twenty-seven of these patients had suffered from angina for some months before admission, and 13 had had one previous myocardial infarction. Evidence of congestive cardiac failure on admission was recorded in 10 patients. The records did not indicate that any patient had had severe 750 
patients suffered from diabetes. Two had complete AV block; in one, this was transient.

\section{RESULTS}

Patients who had been on anticoagulants before admission had this therapy continued. Anticoagulant therapy was initiated for those who developed venous thrombosis. Seventy-five per cent of the patients did not have anticoagulant therapy. The period in hospital varied between 3 and 18 days, the mean time being $13 \cdot 1$ days. The average time between onset of symptoms and hospital admission was 11.6 hours (Mittra, 1965). Of the 102 patients, 64 were discharged to their own homes and 38 to a convalescent hospital some 4 miles distant. In this convalescent hospital all patients were mobile.

There were no deaths in the two weeks after discharge and the records do not indicate any morbidity during this period.

\section{Discussion}

There is much variation in the period of total immobilization and the period in hospital advocated for the patient with acute myocardial infarction. Friedberg (1966) states that, "most of the fatalities and complications from acute myocardial infarction occur during the first week, a more moderate number in the second week and relatively few in the third week. For this reason it is my policy to recommend a minimum of 2 to 3 weeks rest in bed. For an additional period of 3 to 4 weeks (making an average total of 6 weeks), the patient with an acute transmural infarct is confined to bed part or most of the time". Cecil-Loeb Textbook of Medicine (1967) states that, "a patient is usually kept in bed for 2 to 6 weeks". Lawrie et al. (1967) indicate that their patients were discharged on average 4 to 5 weeks after admission. Brummer, Linko, and Kasanen (1956) reported 236 patients with an acute myocardial infarction who were confined to bed on average 16.2 days, the average time in hospital being $22 \cdot 6$ days. Brummer, Linko, and Kallio (1961) reported a further series of 321 patients who were confined to bed for an average of 12 days, their total period in hospital being $20 \cdot 1$ days.

Late development of serious cardiac arrhythmias may be used as an argument against early discharge. Restieaux et al. (1967) reported examples of unpredicted ventricular fibrillation occurring in the second or third week after admission. However, Lawrie et al. (1967) reported that no long-term survivors were found among patients resuscitated from cardiac arrest occurring more than 12 hours after the onset of symptoms. It seems clear that in the management of coronary thrombosis the emphasis should be placed on finding a hospital bed for the patient immediately after the onset of symptoms, if need be at the risk of discharging some patients early in the third week of their illness. The data presented in this paper indicate that this risk is slight.

\section{SUMMARY}

A follow-up study of 102 patients discharged 18 days or less after hospital admission for acute myocardial infarction is presented. The average period in hospital was 13.1 days. The patients represented 55 per cent of all patients aged 70 years or less who survived their stay in hospital in a general medical ward in the period studied.

No patient died in the 2 weeks after discharge. There was no apparent morbidity in the 2-week period after discharge which might have been prevented by a more prolonged stay in hospital. It is suggested that in the management of myocardial infarction the emphasis should be on early admission rather than on a prolonged period in hospital.

I wish to thank Professor G. M. Bull and Dr. R. A. Womersley for their permission to publish the data concerning these patients, all of whom were under their care.

\section{REFERENCES}

Bainton, C. R., and Peterson, D. R. (1963). Deaths from coronary heart disease in persons fifty years of age and younger. A community-wide study. New Engl. f. Med., 268, 569.

Brit. med. F. (1968). Leading article. Immediate coronary care. 3,134 .

Brummer, P., Linko, E., and Kallio, V. (1961). Myocardial infarction treated by early ambulation. Effect of prolonged anticoagulant therapy on the immediate prognosis after discharge from hospital. Amer. Heart $\mathcal{F}$., 62, 478 .

,- , and Kasanen, A. (1956). Myocardial infarction treated by early ambulation. Amer. Heart f., 52, 269.

Cecil-Loeb Textbook of Medicine (1967). 12th ed. Ed. by P. B. Beeson and W. McDermott. Saunders, Philadelphia.

Friedberg, C. K. (1966). Diseases of the Heart, 3rd ed. Saunders, Philadelphia and London.

Lawrie, D. M., Greenwood, T. W., Goddard, M., Harvey, A. C., Donald, K. W., Julian, D. G., and Oliver, M. F. (1967). A coronary-care unit in the routine management of acute myocardial infarction. Lancet, 2, 109.

McNeilly, R. H., and Pemberton, J. (1968). Duration of last attack in 998 fatal cases of coronary artery disease and its relation to possible cardiac resuscitation. Brit. med. F., 3, 139.

Mittra, B. (1965). Potassium, glucose, and insulin in treatment of myocardial infarction. Lancet, 2, 607.

Pantridge, J. F., and Geddes, J. S. (1966). Cardiac arrest after myocardial infarction. Lancet, 1, 807.

$\longrightarrow$, and - (1967). A mobile intensive-care unit in the management of myocardial infarction. Lancet, $2,271$. 
Restieaux, N., Bray, C., Bullard, H., Murray, M., Robinson, J., Brigden, W., and McDonald, L. (1967). 150 patients with cardiac infarction treated in a coronary unit. Lancet, 1, 1285.

Yater, W. M., Traum, A. H., Brown, W. G., Fitzgerald,
R. P., Geisler, M. A., and Wilcox, B. B. (1948). Coronary artery disease in men eighteen to thirty-nine years of age. Report of eight hundred and sixty-six cases, four hundred fifty with necropsy examination. Amer. Heart F., 36, 334, 481, and 683 . 